\title{
Factors Reshaping the Financing of Higher Education in the 1970's
}

\author{
Michael Oliver*
}

During the 1960's Canadian universities were transformed from predominantly private institutions to public institutions and from individual institutions to elements of provincial systems of higher education. They grew in student numbers and therefore in size and cost. They shifted, as did the whole domain of education, from the periphery of public policy to a position close to its centre.

Someone shook the kaleidoscope as the 1970's began and a startling new pattern took shape. Education gave way to environmental problems, resource policy or transportation as priorities changed in provincial capitals. Within the sphere of post-secondary education itself, the universities shared public attention with community colleges or CAAT's or CEGEP's. Most university people had welcomed the burgeoning of these new institutions in the 1960's for they shared a load that was becoming too heavy for the universities, and permitted a division of function that enabled the universities to concentrate on the things they could do best. But by 1971-72 the colleges began to look like competitors for a scarce resource, for the unthinkable happened: the rise in student numbers, the salient feature of the 1960's, began to taper off.

At first, it was only a matter of the actual increases in enrolment falling substantially below predictions. By 1973, for Canada as a whole, the university population stopped growing. Whether the halt is permanent or temporary, no one knows. Neither our demographers nor our back-of-the-envelope calculators have had time to put together new models. We know what has happened in more detail now. It is not just a matter of first-year enrolments falling off from projections, there have been upper-year drop-out increases, and reductions in graduate enrolments as well. But we still are far from a complete answer as to why all this has occurred. Hypotheses abound, but none of us is so sure of his explanation that he can confidently build it into a new set of projections for the future.

Renewed growth is unlikely to come from population increases alone. By the late 1970 's, the rate of growth of the 18 to 24 age group will have levelled off con-

* Michael Oliver, President, Carleton University, Ottawa, 
siderably. Drop-out rates from all senior years in Ontario high schools are unexpectedly high, so that the percentage of eligible university entrants from this pool may be lower than in the past. If the flattened growth curve for Canadian universities is to renew its rise, students' demand for higher education must be restored. This may well happen, but it is less probable that the shape of the new growth will be the same as that of the past. A renewed demand could well favour part-time over full-time study or express itself in a preference for work-study combinations. We may see the realization of that oft-repeated prediction that education in the future will be a life-long process. Enrolments have fallen more in arts programs than in professional, career-oriented studies. Indeed, there are still serious shortages of space and facilities for health sciences training and short-falls in the supply needed to meet the country's requirements. If enrolments do rise again, will the humanities recover, will the social sciences resume their expansion, or will the biological sciences, management, environmental studies or communications seize the lion's share of growth ? None of these questions is easily answered, but they would be less disturbing questions if so much did not hang on an accurate reply.

No institution finds it easy to adapt to sudden changes, especially when these take the form of contraction. But it is evident that when a down-turn occurs, an institution in which costs vary much more slowly than revenues is going to be in greater trouble than one whose expenditures and income move in phase. In most provinces, the universities find themselves in the former position. During the 1960's, many provinces adopted systems of financing universities that were adequate and even generous for a period of growth. The shortcomings of these methods for institutions that are contracting or growing at a much lesser rate than that planned for are becoming woefully evident.

A quick review of the ways governments began to finance Canadian universities in the 1960's, and of some of the reasons why one method or another was chosen, may be useful, for the 1960's begin to look different when we examine them from the stand point of 1973 .

First it must be said that, on the whole, governments in the 1960 's treated Canadian universities with care and respect. The provinces and the federal government sought diligently and with imagination for ways to transfer very large sums to the universities without unduly restricting their freedom of choice. The universities were asked to expand, to reach out into sectors of the population that had never before aspired to higher education, but no detailed controls on their development were imposed. $\mathrm{He}$ who paid the piper called the tempo and the key, but rarely the tune.

Although the way a balance between respect for university autonomy and the need to account for public funds was achieved varied from province to province, one feature of financing policy was common to all. Because growth in student numbers was both a fact and a goal, grants grew as enrolments increased. To one degree or another, 
budgets became tied to student numbers. But the degree of student-relatedness did vary, and the full import of these differences has only become clear in the 1970's.*

Ontario pioneered a system for funding operating expenses based on weighted student numbers that became a model for many other parts of Canada. It was adapted with special variations in Manitoba, and, until this year, in Newfoundland and Prince Edward Island. It entered into practices of both Nova Scotia and, to a lesser but still appreciable extent, New Brunswick. Indeed, the influence of the Ontario model was such that the expression "formula financing" became a synonym for funding based on weighted student numbers, although other types of formula are, of course, quite conceivable. Quebec, Saskatchewan, Alberta and British Columbia gave the single factor of enrolment size and distribution a lesser place in their schemes for providing operating funds, but can hardly be seen as forming a grouping of provinces in any other sense, for procedures in each tended to be sui generis.

The high prestige enjoyed by the weighted-enrolment formula is readily explained. Through its use, each university's allotment of operating funds could be determined objectively, and in a readily verifiable fashion, without governmental examination of university accounts and expenditure decisions. A university's autoniomy was, it seemed, fully protected at the same time as it received equitable treatment in relation to sister institutions. By contrast, universities funded by a percentage increase over previous years' budgets, plus adjustments, (as in Quebec) worried about the perpetuation of past inequities, and universities financed by negotiation and consultation with government (as in Saskatchewan or British Columbia) worried about the possibility of political favour or disfavour affecting their incomes.

In the following paragraphs some rather harsh judgments will be passed on student-number-based formula financing, but it is important that these comments be prefaced by a strong endorsation of the goals of formula financing : the elimination of arbitrariness and the provision of funds without detailed control of expenditures. They remain paramount objectives, but the means by which they are achieved need close scrutiny.

During the 1960's demand for university education was high; it was public policy to meet this demand, and it was suspected that universities might be reluctant to do so. Given these conditions, increasing operating funds in direct proportion to increases in student numbers seemed a sensible policy. Universities had to be induced to develop a growth mentality. Moreover, the universities were furnished with ample building space and equipment, and the amount of revenue provided for each new student was the average cost of educating a student in a given program. Under these circumstances, the

* For a rundown of provincial policy for financing universities, see articles by Audrey Gill in University Affairs, January 1973. 
incentive to expand enrolment was strong indeed, for the fixed costs of heat, light, maintenance and administration loomed less large as numbers increased, and the marginal cost of an extra student might approach zero. The pattern of growth might have developed some oddities, particularly if the average cost of one program had been estimated at too high a figure and that of another too low, for then the method of financing would have a steering effect. Indeed, as per student costs for a given program were unlikely to be identical in each institution, yet the revenues produced by adding a student were the same across the system, some steering effect was inevitable. These were perhaps tolerable distortions when everything had to expand, but even then they might produce high growth rates in low priority areas (from the standpoint of provincial policy) and low growth rates in high priority sectors.

What happens now if student demand falls and growth is no longer an objective of public policy? University income will be decreased more than the decrease in cost for every student lost, because fixed costs must still be met. It becomes vital to prevent student numbers from falling and the mild competition for students between institutions that characterized the period of general growth becomes a scramble to prevent deficits from mounting. Recruitment campaigns gain in ingenuity and lose in dignity, scholarships become elements in a price war, standards are jeopardized and any special entry condition that seems to make one institution less attractive than another is speedily jettisoned with scant consideration for its academic or social merit.

It would be agreeable if this were more of a caricature than it is. It would be nice to be sure that the decisions of successive universities to abandon SACU tests were based on a conviction that the tests were of no value, rather than on a worry that retaining the tests would leave them at a competitive disadvantage. One would like to believe it was not concern about student numbers that has led one English-language university after another to drop French as a required subject, in spite of federal policies on bilingualism. It would be comforting to be certain that the sudden increase in entrance scholarship funds this year was solely motivated by a desire to ensure higher education for bright students. Are especially strong efforts to attract graduate students to Ontario universities always explained by a conviction that more Ph.D.'s are required, or sometimes by the knowledge that each Ph.D. student is worth six basic income units?

If it seems that the blame for a worrisome situation is being isolated either in individual universities or in particular governments, this impression should be corrected. Where student-number-based formulae were established in Canadian provinces, they were accepted by both universities and governments. Once installed, the systems had their own inner dynamics and a single university must either be well endowed with private funds or possessed of a board of governors willing to take enormous risks if it is to hold out against the pressures to maintain student numbers by all available means. Unfortunately, many efforts will be self-defeating, for one university quickly matches whatever methods its sister institutions use to gain a competitive edge. In the strange world they enter when 
recruitment drives intensify, universities may even be subsidizing the public purse with their private funds, for scholarships that substitute for student aid have just this effect.

If enrolments continue to level off or fall in provinces where enrolment-based formulae determine operating funds, some universities will inevitably have to cut their expenditures quite drastically, others less so, for the impact of reduced student numbers will fall unequally. The smaller, younger institutions will generally feel the pinch most, unless they are bolstered by extra-formula grants. Sometimes, on academic or public interest grounds, these may be the institutions that should curtail their activities, but this will be pure coincidence. (This brings up the whole question of planning, for even the most carefully designed system of financing will have to be modified by policy decisions if the waste of unused resources, on one hand, and over-used resources, on the other, is to be avoided.) Even if one makes the dubious assumption that the hard-hit institutions are those that should reduce their expenditures most, the problem of adjustment time must be faced. The effects on budgets of student losses can be postponed for a year if slip-year financing is used, as is now the case in Ontario and as was the case in Nova Scotia up until 1969-70, but this still may not provide sufficient leeway for budget reductions to be made with care and equity. The difficulties of reducing the academic staff, due to tenure provisions, or unionized staff, due to job security provisions, may cause the non-unionized support staff to be unduly penalized or student services to be starved or, less serious, but still wasteful, capital equipment to deteriorate due to inadequate maintenance. A strict adherence to the student-based formula will provide little room for good sense to operate.

To recapitulate the main point briefly, the university financing system that seemed during the 1960 's to provide an objective, calculable, unconstrained income to universities has shown grave, indeed intolerable, weaknesses in the early 1970's. The conclusion to be drawn from this is not that the search for objective formulae is illusory, but that a formula based on weighted student numbers (or, probably, on any other single base) is inadequate.

What are the most promising avenues for improvement? There is no lack of suggestions, for several Canadian provinces have undertaken enquiries on post-secondary education recently, and other nations, faced with comparable problems, have produced reports and analyses in some profusion. No attempt will be made to review even the Canadian literature on university financing. Rather, a few propositions that seem most promising will be mentioned and will be followed by some gratuitous and probably not very helpful words of advice.

First, it seems unlikely that a single formula for determining operating grants will suffice. The difficulties of using weighted student numbers are demonstrable, but with any imagination similar or worse problems can be predicted if number of courses, or programs, or student-contact hours, or any other single measure were to be substituted. Some of the problems of using student numbers would be solved if stability and predict- 
ability were increased by the universities and public authorities arriving at agreed enrolment projections for the subsequent year, as proposed in the Report of the Commission on Post-Secondary Education in Ontario (p. 144), but disparities in costs between institutions and the need to maintain overhead expenditures even when enrolment declines would still create nasty difficulties.

A more promising approach is to divide university budgets into a number of component parts and work towards an appropriate formula for the financing of each part. The Commission on Post-Secondary Education report moves in this direction with its proposal to separate instructional costs and research costs (pp. 141-2), but it may be suggested that it goes both too far and not far enough : too far, in that it seeks to cost out that portion of a professor's time that is devoted to research and that devoted to teaching (with possible steering effects horrendous to contemplate, depending on each institution's calculation of the comparative advantage of devoting staff time to one activity or the other) ; not far enough, in that variations in cost structure between small and large institutions and between those with specialized missions and those with a full range of activities will not be taken sufficiently into account.

Quebec is moving towards separate formulae for salary costs and for a number of other broadly defined cost categories, and a somewhat similar approach has been put forward in the position paper on finance issued by the Task Force on Post-Secondary Education in Manitoba. The Manitoba Task Force suggests that university budgets be separated into nine categories : "first claims" (on fixed payments or previously incurred indebtedness), maintenance expenditures, ancillary services, administration (academic), administrative support services, research (overheads), academic costs, community service and capital costs. Whenever possible, objective criteria for funding would be established ; for example, costs per square foot for maintenance ; and special indices for computer and library costs. Community service costs are recognized, it is proposed, for provision of public access to library, computer, and other university facilities. Academic costs would cover all professors' salaries plus other instructional costs, and would be based on a student numbers formula, with weights determined by a cost study particular to each institution. Weights would be telescoped to a maximum spread of six points, in contrast to the current fourteen.

Finally, there are some additional criteria by which any financing system for universities might be judged.

1. The system should not put a premium on growth for growth's sake.

2. It should permit a variety amongst institutions rather than promoting standardization and duplication.

3. It should give equal encouragement to part-time and full-time education and foster life-long education. 
4. It should avoid emphasizing the certification functions of universities and encourage learning itself.

5. It should be closely integrated with the financing of all post-secondary education, so that effective planning for all who wish to continue studies beyond school can be achieved.

6. It should recognize the interrelationship between teaching and research in the universities and not artificially and accidentally foster one at the expense of the other.

7. It should permit a broad range of autonomous decision making to each institution and not be an instrument for detailed external controls.

8. It should provide reasonable budgetary stability while at the same time fostering innovation.

This is far from an exhaustive listing, but perhaps it will suffice to indicate how difficult it is to evolve a really satisfactory method of financing university operations. Capital funding has not been touched on, and no apology is made for the omission. There can be little doubt that the problems of operating grants are by far the most pressing in the early 1970's.

Canada has a university tradition that suffers little from comparison with other countries. We have shown some imagination in our attempts to meet the financial needs of higher education, and we can remain optimistic that we can build on our achievements and learn from our mistakes. 